\title{
Spinal Instead of General Anesthesia for Two Pediatric Patients at Risk for Malignant Hyperthermia
}

\author{
Ambrish B. Patel ${ }^{\mathrm{a}, \mathrm{c}}$, Emmett Whitaker ${ }^{\mathrm{b}}$, Richard S. Cartabuke ${ }^{\mathrm{b}}$, \\ Gina Fedel ${ }^{\mathrm{b}}$, Joseph D. Tobias ${ }^{\mathrm{b}}$
}

\begin{abstract}
Although commonly practiced in the adult population, the use of spinal anesthesia has been limited in infants and children. Historically, it was employed as a means of avoiding apnea following general anesthesia or avoiding the need for endotracheal intubation. More recently, there has been resurgence in the use of spinal anesthesia due to concerns that general anesthetic agents may exert neurotoxic effects and impact future neurocognitive function. More broadly, spinal anesthesia may also have applications in patients with co-morbid conditions that increase the risk of general anesthesia. We present the use of spinal anesthesia as a means of avoiding general anesthesia in two infants with family histories of malignant hyperthermia.
\end{abstract}

Keywords: Malignant hyperthermia; Spinal anesthesia; Pediatrics

\section{Introduction}

Malignant hyperthermia $(\mathrm{MH})$ is an inherited disorder, characterized by a hypermetabolic state following exposure to succinylcholine or volatile anesthetic agents. This rare phenomenon occurs in approximately 0.66 per 100,000 pediatric patients [1]. The pathophysiology relates to the exaggerated intracellular release of calcium from the sarcoplasmic reticulum. Susceptible patients often have mutations in the ryanodine receptor (RYR1) or dihydropyridine (DHP) receptor, leading to unregulated calcium release following exposure to triggering agents [2]. The unregulated increase in intracellular calcium leads to accelerated muscle contraction resulting in hypercar-

Manuscript submitted May 31, 2017, accepted June 21, 2017

aDivision of Pediatric Critical Care Medicine, Department of Pediatrics, Nationwide Children's Hospital and The Ohio State University, Columbus, $\mathrm{OH}$, USA

bDepartment of Anesthesiology \& Pain Medicine, Nationwide Children's Hospital and The Ohio State University College of Medicine, Columbus, $\mathrm{OH}$, USA

${ }^{\mathrm{c} C}$ Corresponding Author: Ambrish B. Patel, Division of Pediatric Critical Care Medicine, Nationwide Children's Hospital, 700 Children's Drive, Columbus, OH 43205, USA. Email: Ambrish.Patel@Nationwidechildrens.org

doi: https://doi.org/10.14740/jmc2854w bia, hyperthermia, metabolic acidosis, and rhabdomyolysis. If untreated, the process has a high mortality rate [3]. Treatment includes early recognition, removal of the inciting agent, management of the systemic complications, and the administration of dantrolene [4]. In susceptible patients or in patients with a family history of $\mathrm{MH}$, general anesthesia can be provided with the use of non-triggering agents including nitrous oxide and intravenous agents (propofol, ketamine, dexmedetomidine, opioids, and midazolam) [4].

Alternatively, for specific surgical procedures, spinal anesthesia can be used in place of general anesthesia. Spinal anesthesia was first reported in infants and children in the late 19th and early 20th century when the potential for morbidity and mortality from general anesthesia was significant $[5,6]$. Spinal anesthesia saw a resurgence during the 1980s when it was used in former preterm infants as a means of avoiding intraoperative intubation in patients with underlying bronchopulmonary dysplasia (BPD), as well as apnea and respiratory insufficiency following general anesthesia with halothane [7, 8]. However, enthusiasm waned as the risk of apnea was shown to be less likely when newer inhalational anesthetic agents were introduced into clinical practice $[9,10]$. Moreover, the introduction of surfactant and the improved management of mechanical ventilation in preterm infants have changed the acuity of BPD, reducing the severity of the underlying respiratory disease [11]. More recently, there has been a renewed interest in the use of spinal anesthesia as an alternative to general anesthesia due to concerns raised by laboratory and animal studies suggesting that exposure to certain anesthetic agents is neurotoxic and may be associated with long-term neurocognitive effects $[12,13]$. Although the evidence demonstrating an actual clinical effect on long-term human neurocognitive outcomes is equivocal, our center has initiated a program providing spinal anesthesia instead of general anesthesia for many surgical procedures in infants and children $[14,15]$. Spinal anesthesia may also have a role as a means of avoiding general anesthesia in specific patient populations with co-morbid diseases associated with an increased risk of general anesthesia. We present the use of spinal anesthesia as a means of avoiding general anesthesia in two infants with a family history of $\mathrm{MH}$.

\section{Case Reports}

At Nationwide Children's Hospital, formal Institutional Re- 
view Board approval is not required for case presentations involving two or fewer patients.

\section{Case 1}

An 8-month-old, 10-kg boy with a hidden penis, penoscrotal webbing, and phimosis, presented for elective buried penis repair, complex scrotoplasty, and circumcision. The boy was otherwise healthy and there was no prior history of general anesthesia. His family history was notable for $\mathrm{MH}$ in both the father and paternal grandmother. Due to the potential risks of $\mathrm{MH}$ in this patient, spinal anesthesia was discussed with the parents and selected for the operative procedure. On the day of surgery, the infant was held nil per os (NPO) for solids for $6 \mathrm{~h}$ and clear liquids for $2 \mathrm{~h}$. A topical anesthetic cream was placed over the lumbar area and the patient was transported to the operating room. Spinal anesthesia was placed using a 1.5inch, 22-gauge spinal needle, which was inserted at the L3-4 interspace. Following free flow of cerebrospinal fluid (CSF), $1.2 \mathrm{~mL}$ of isobaric $0.5 \%$ bupivacaine $(0.6 \mathrm{mg} / \mathrm{kg}$ bupivacaine $)$ with epinephrine $1: 200,000$ and $10 \mu \mathrm{g}$ of clonidine was injected. Routine American Society of Anesthesiologists' (ASA) monitors were placed. Adequate surgical anesthesia with sensory and motor blockade was attained. A peripheral intravenous catheter was placed in the foot after the onset of sensory blockade. No intraoperative medications were required to supplement the spinal anesthesia or provide sedation. No clinically significant respiratory or hemodynamic changes were noted. There were no clinical signs of $\mathrm{MH}$. The surgical procedure lasted for approximately $1 \mathrm{~h}$. The patient was transferred to the post anesthesia care unit (PACU) for recovery. Postoperatively, a single dose of fentanyl $(1 \mu \mathrm{g} / \mathrm{kg})$ was administered for irritability. His postoperative course was unremarkable and he was discharged home after $3 \mathrm{~h}$ of monitoring.

\section{Case 2}

A 9-month-old, 10.5-kg boy with a right ectopic testicle and penile adhesions, presented for elective right orchidopexy and lysis of penile adhesions with circumcision. The infant was otherwise healthy with no prior anesthesia or surgical history. His family history was notable for $\mathrm{MH}$ in a maternal nephew. Due to the potential risks of $\mathrm{MH}$ in this patient, spinal anesthesia was discussed with the parents and selected for the operative procedure. On the day of surgery, the infant was held NPO for solids for $6 \mathrm{~h}$ and clear liquids for $2 \mathrm{~h}$. A topical anesthetic cream was placed over the lumbar area and the patient was transported to the operating room. Spinal anesthesia was provided using a 1.5-inch, 25-gauge spinal needle, which was inserted at the L3-4 interspace. Following free flow of CSF, $1.2 \mathrm{~mL}$ of isobaric $0.5 \%$ bupivacaine $(0.6 \mathrm{mg} / \mathrm{kg}$ bupivacaine $)$ with epinephrine $1: 200,000$ and $10 \mu \mathrm{g}$ of clonidine was injected. Routine ASA monitors were placed. Adequate anesthesia with sensory and motor blockade was attained. A peripheral intravenous catheter was inserted in the foot after the onset of sensory blockade. No intraoperative medications were required to supplement the spinal anesthesia or provide sedation.
No clinically significant respiratory or hemodynamic changes were noted. There were no clinical signs of MH. The surgical procedure lasted approximately $1.25 \mathrm{~h}$. The patient was transferred to the PACU and discharged home after $1 \mathrm{~h}$ of monitoring following an unremarkable postoperative course.

\section{Discussion}

Although used most commonly to avoid the deleterious effects of general anesthesia on the central control of ventilation, to avoid the need for endotracheal intubation, or to avoid the potential neurocognitive effects of general anesthetic agents, there are many co-morbid conditions which may increase the risk of general anesthesia [16]. In the two patients described, spinal anesthesia was chosen instead of general anesthesia due to the potential for increased morbidity given the patients' family history of MH. Spinal anesthesia effectively provided surgical anesthesia for the urologic procedures, thereby avoiding the need for general anesthesia. Neither patient required intraoperative sedative or analgesic medications and maintained hemodynamic stability without signs of $\mathrm{MH}$. The postoperative PACU stay of the first patient was prolonged because a dose of fentanyl $(1 \mu \mathrm{g} / \mathrm{kg})$ was administered, mandating longer monitoring per our institutional guidelines. Our second patient highlights another benefit of spinal anesthesia as he required no postoperative analgesic or sedation medications, and therefore was discharged rapidly from the PACU to the phase two recovery area.

Previous reports of the use of spinal anesthesia in MH susceptible adult patients are outlined in Table 1 [17-23]. Adverse effects were rare with hypotension noted in one parturient and respiratory difficulties in another patient related to a high spinal block (T3) and the concomitant administration of dantrolene. Our two patients represent the first reports of the use of spinal anesthesia in potentially $\mathrm{MH}$-susceptible pediatric patients. Overall, these reports and our experiences demonstrate the safe and effective use of spinal anesthesia as an alternative to general anesthesia in patients at risk for $\mathrm{MH}$ due to their previous anesthetic history or family history.

Although generally considered safe in patients with $\mathrm{MH}$, anecdotal reports suggest the onset of $\mathrm{MH}$ following neuraxial (spinal or epidural) anesthesia [24-26]. These anecdotal reports include MH-like symptoms after neuraxial administration of both ester (tetracaine) and amide (bupivacaine) local anesthetic agents. Sheu et al describe the potential development of $\mathrm{MH}$ following spinal anesthesia with tetracaine in a 62-year-old patient undergoing transurethral resection of the prostate [27]. Caffeine-halothane contracture testing was not available and while MH was unable to be confirmed, the author reported a hypermetabolic state demonstrating features of acute rhabdomyolysis. Albeit rare, the potential to trigger $\mathrm{MH}$ with neuraxial anesthesia mandates appropriate intraoperative and postoperative monitoring of temperature and physiologic function. Dantrolene should be available for specific treatment of $\mathrm{MH}$.

Adverse effects related to spinal anesthesia are generally low, especially in the pediatric population. Relative contraindi- 
Table 1. Use of Spinal Anesthesia in MH Susceptible Patients [17-23]

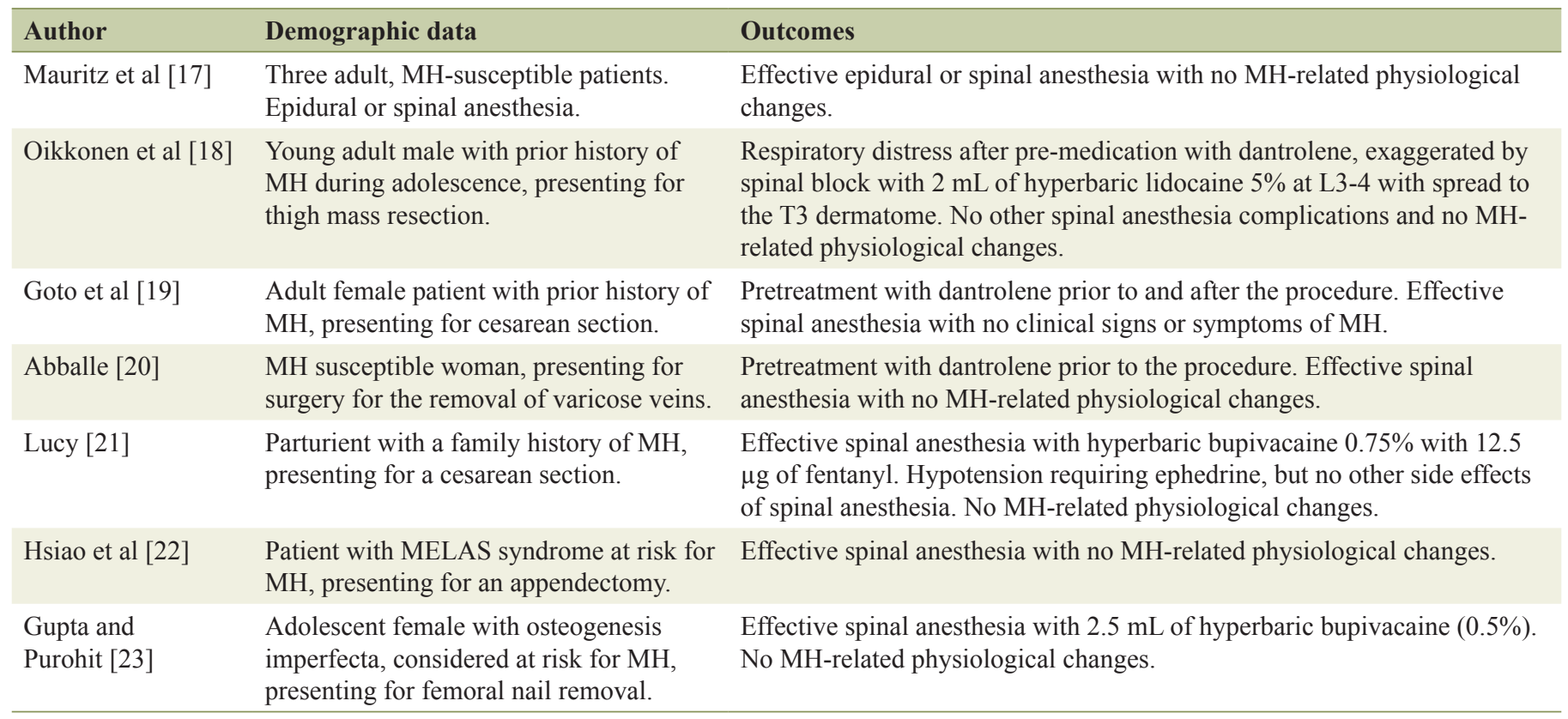

$\mathrm{MH}$ : malignant hyperthermia.

cations include uncorrected coagulopathy, localized infection at the insertion site, and evidence of intracranial hypertension. Given the later development of the sympathetic nervous system, hypotension is rare and in fact, blood pressure stability is better with spinal anesthesia than general anesthesia [28]. Post-dural puncture headache (PDPH) remains uncommon in pediatric patients less than 10 - 12 years of age when compared to the adult population [29]. Other neurological complications that may occur from spinal anesthesia are rare, including subdural hematoma formation. Anecdotal reports suggest that such complications generally occur in the setting of co-morbid defects of coagulation function [30].

Developed over the past 24 months, the following outlines our standard practice for spinal anesthesia from our institution. The intrathecal space is accessed using a 1.5-inch, 22-gauge or a 1.5-inch, 25-gauge spinal needle (Becton Dickinson, Franklin Lakes, NJ, USA). The local anesthetic used is preservativefree isobaric bupivacaine $(0.5 \%)$ in a dose of $0.2 \mathrm{~mL} / \mathrm{kg}(1$ $\mathrm{mg} / \mathrm{kg})$. The maximum dose is generally $1 \mathrm{~mL}(5 \mathrm{mg})$ in most infants. However, for longer procedures or larger children, a higher total volume can be used $(1.2 \mathrm{~mL}$ or $6 \mathrm{mg})$. To prolong the duration of the surgical block and maximize postoperative analgesia, the syringe is washed with 1:1,000 epinephrine prior to filling it with the local anesthetic agent and clonidine (1 $\mu \mathrm{g} / \mathrm{kg}$ ) is added to the solution $[31,32]$.

With its excellent safety profile, spinal anesthesia is a useful alternative to general anesthesia in patients with a past history or family history of $\mathrm{MH}$. Our pediatric cases highlight the benefits of spinal anesthesia instead of general anesthesia in patients with co-morbid conditions. With concerns for respiratory complications following general anesthesia with the volatile agents and ongoing controversy regarding the potential long-term neurocognitive outcomes of general anesthesia, spinal anesthesia may have a larger role in the anesthetic management of pediatric patients.

\section{Conflict of Interest}

No conflict of interest for any authors.

\section{References}

1. Brady JE, Sun LS, Rosenberg H, Li G. Prevalence of malignant hyperthermia due to anesthesia in New York State, 2001-2005. Anesth Analg. 2009;109(4):1162-1166.

2. Andronache Z, Hamilton SL, Dirksen RT, Melzer W. A retrograde signal from RyR1 alters DHP receptor inactivation and limits window $\mathrm{Ca} 2+$ release in muscle fibers of Y 522S RyR1 knock-in mice. Proc Natl Acad Sci U S A. 2009;106(11):4531-4536.

3. Gronert GA, Theye RA. Halothane-induced porcine malignant hyperthermia: metabolic and hemodynamic changes. Anesthesiology. 1976;44(1):36-43.

4. Naguib A, McKee C, Phillips A, Tobias JD. Dexmedetomidine as the primary anesthetic agent during cardiac surgery in an infant with a family history of malignant hyperthermia. Saudi J Anaesth. 2011;5(4):426-429.

5. Bier A. Experiment regarding the cocainization of the spinal cord. Zentralbl Chir. 1899;51:361-369.

6. Bainbridge W. A report of twelve operations on infants and young children during spinal anesthesia. Arch Pediatr. 1901;18:570-574.

7. Welborn LG, Hannallah RS, Luban NL, Fink R, Ruttimann UE. Anemia and postoperative apnea in former pre- 
term infants. Anesthesiology. 1991;74(6):1003-1006.

8. Krane EJ, Haberkern CM, Jacobson LE. Postoperative apnea, bradycardia, and oxygen desaturation in formerly premature infants: prospective comparison of spinal and general anesthesia. Anesth Analg. 1995;80(1):7-13.

9. William JM, Stoddart PA, Williams SA, Wolf AR. Postoperative recovery after inguinal herniotomy in ex-premature infants: comparison between sevoflurane and spinal anaesthesia. Br J Anaesth. 2001;86(3):366-371.

10. Sale SM, Read JA, Stoddart PA, Wolf AR. Prospective comparison of sevoflurane and desflurane in formerly premature infants undergoing inguinal herniotomy. Br J Anaesth. 2006;96(6):774-778.

11. Merritt TA, Deming DD, Boynton BR. The 'new' bronchopulmonary dysplasia: challenges and commentary. Semin Fetal Neonatal Med. 2009;14(6):345-357.

12. Jevtovic-Todorovic V, Hartman RE, Izumi Y, Benshoff ND, Dikranian K, Zorumski CF, Olney JW, et al. Early exposure to common anesthetic agents causes widespread neurodegeneration in the developing rat brain and persistent learning deficits. J Neurosci. 2003;23(3):876-882.

13. Coleman K, Robertson ND, Dissen GA, Neuringer MD, Martin LD, Cuzon Carlson VC, Kroenke C, et al. Isoflurane anesthesia has long-term consequences on motor and behavioral development in infant rhesus macaques. Anesthesiology. 2017;126(1):74-84.

14. Davidson AJ, Disma N, de Graaff JC, Withington DE, Dorris L, Bell G, Stargatt R, et al. Neurodevelopmental outcome at 2 years of age after general anaesthesia and awake-regional anaesthesia in infancy (GAS): an international multicentre, randomised controlled trial. Lancet. 2016;387(10015):239-250.

15. Sun LS, Li G, Miller TL, Salorio C, Byrne MW, Bellinger $\mathrm{DC}$, Ing $\mathrm{C}$, et al. Association between a single general anesthesia exposure before age 36 months and neurocognitive outcomes in later childhood. JAMA. 2016;315(21):2312-2320.

16. Kumar KR, Kumar H, Baidya DK, Arora MK. Successful use of spinal anesthesia for inguinal hernia repair in a child with Hunter syndrome with difficult airway. J Clin Anesth. 2016;30:99-100.

17. Mauritz W, Hackl W, Winkler M, Sporn P, Steinbereithner K. Anesthesia in malignant hyperthermia susceptible patients. Acta Anaesthesiol Belg. 1990;41(2):87-94.

18. Oikkonen M, Rosenberg PH, Bjorkenheim JM, Paetau A, Huopaniemi T. Spinal block, after dantrolene pretreatment, for resection of a thigh muscle herniation in a young malignant hyperthermia susceptible man. Acta Anaesthesiol Scand. 1987;31(4):309-311.

19. Goto S, Ogata K, Fujie T, Fujigaki T, Nakamura H, Yuki- nari T, Shibata O. [Caesarean section in a patient with past history of fulminant malignant hyperthermia]. Masui. 1993;42(2):271-275.

20. Abballe C, Primieri P, De Cosmo G. [The use of subarachnoid bupivacaine analgesia in malignant hyperthermia-susceptible subjects. A clinical case report]. Minerva Anestesiol. 1993;59(6):335-338.

21. Lucy SJ. Anaesthesia for caesarean delivery of a malignant hyperthermia susceptible parturient. Can J Anaesth. 1994;41(12):1220-1226.

22. Hsiao PN, Cheng YJ, Tseng HC, Chuang YH, Kao PF, Tsai SK. Spinal anesthesia in MELAS syndrome: a case with mitochondrial myopathy, encephalopathy, lactic acidosis and stroke-like episodes. Acta Anaesthesiol Sin. 2000;38(2):107-110.

23. Gupta D, Purohit A. Anesthetic management in a patient with osteogenesis imperfecta for rush nail removal in femur. Anesth Essays Res. 2016;10(3):677-679.

24. Motegi Y, Shirai M, Arai M, Kato S, Kawana Y, Goto F. Malignant hyperthermia during epidural anesthesia. J Clin Anesth. 1996;8(2):157-160.

25. Kemp DR, Choong LS. Malignant hyperthermia and the conscious patient. Aust N Z J Surg. 1988;58(5):423-427.

26. Katz JD, Krich LB. Acute febrile reaction complicating spinal anaesthesia in a survivor of malignant hyperthermia. Can Anaesth Soc J. 1976;23(3):285-289.

27. Sheu CC, Tsai JR, Hung JY. Possible malignant hyperthermia during spinal anaesthesia with tetracaine. Anaesthesia. 2007;62(2):200-201.

28. McCann ME, Withington DE, Arnup SJ, Davidson AJ, Disma N, Frawley G, Morton NS, et al. Differences in blood pressure in infants after general anesthesia compared to awake regional anesthesia (GAS Study-A Prospective Randomized Trial). Anesth Analg. 2017;125(3):837-845.

29. Wee LH, Lam F, Cranston AJ. The incidence of post dural puncture headache in children. Anaesthesia. 1996;51(12):1164-1166.

30. Balaban O, Veneziano G, Cartabuke R, Tobias JD. Central nervous system hemorrhage following lumbar puncture for intrathecal chemotherapy in a pediatric oncology patient. J Med Cases. 2016;7:461-766.

31. Cao JP, Miao XY, Liu J, Shi XY. An evaluation of intrathecal bupivacaine combined with intrathecal or intravenous clonidine in children undergoing orthopedic surgery: a randomized double-blinded study. Paediatr Anaesth. 2011;21(4):399-405.

32. Rochette A, Raux O, Troncin R, Dadure C, Verdier R, Capdevila $\mathrm{X}$. Clonidine prolongs spinal anesthesia in newborns: a prospective dose-ranging study. Anesth Analg. 2004;98(1):56-59, table of contents. 